Journal of

Education and Practice

(JEP)

KENYAN EDUCATION IN THE WAKE OF CONSUMERISM: EFFECTS ON FUNDING ANDOUALITY

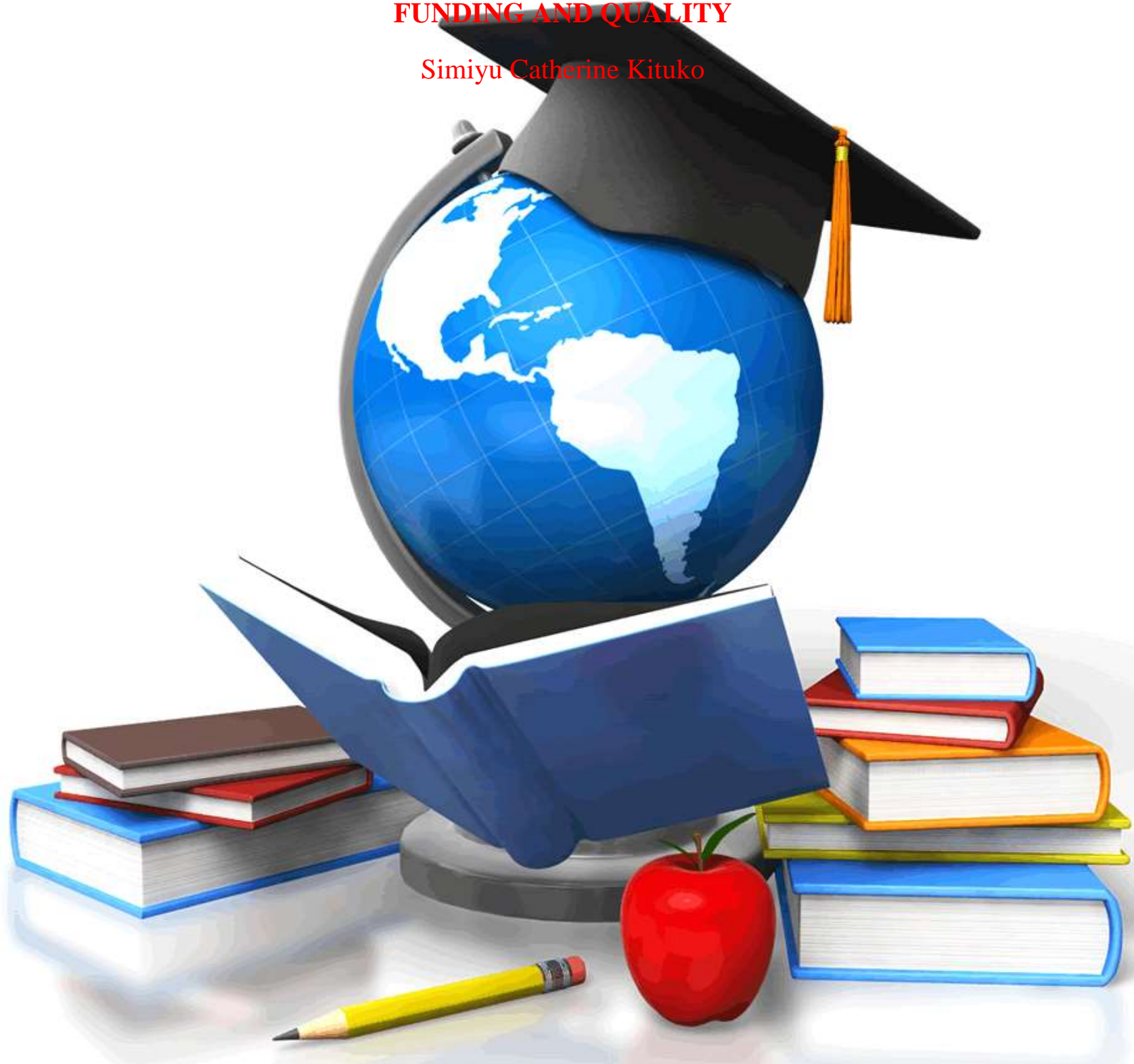

CARI 


\title{
KENYAN EDUCATION IN THE WAKE OF CONSUMERISM: EFFECTS ON FUNDING AND QUALITY
}

\author{
*Simiyu Catherine Kituko \\ Faculty member: School of Education, \\ Moi University \\ *Corresponding Author Email: catherinesimiyu@ mu.ac.ke \\ kitukatwa@gmail.com
}

\begin{abstract}
Education is key for any form of personal or societal development. Citizens who can read, calculate, and think critically are a country's great resource as they have better economic opportunities, higher agricultural productivity, healthier children, and better reproductive health. In her drive towards realization of the Vision 2030 therefore, Kenya highlights education and training as crucial components of the Social Pillar. This is with the understanding that knowledge is important for growth and development of economies. Yet, it is not just education for its own sake, but quality education to serve as a lever for personal development so that the capable and active citizens can in-turn be the strongest lever for long term sustainable change. There is however an emerging trend, consumerism, which thrives on pleasure seeking morality and hedonistic lifestyle while promoting intellectual inactivity. One only needs to have money to pay, often, for one's wants. How this money is obtained is not the issue. This certainly is at crossroads with the ideals of a holistic education which emphasizes virtues such as creativity, honesty and social integration. The purpose of this study was to examine the complexity of funding for quality education in a consumer heightened economy. The method of investigation was content analysis. The paper recommends an overhaul in the Kenyan education award system to ingrain human values of honesty and integrity. This would enhance the policy of quality education for sustainable economic growth.
\end{abstract}

Key words: Consumerism, consumerist culture, funding, Kenyan education, quality education.

\section{INTRODUCTION}

Kenya, like most developing countries, is experiencing a new wave of demand for education basically at all levels and in all fields (Simiyu, 2012). Apart from personal benefits such as obtaining social skills, reformation of attitudes and conferrement of status, education trains in skills that are required by the economy, acts as an integrative force in society by communicating values that unite different sections of society, and promotes cultural heritage (Agarwal, n.d). Unity is required to construct ideas and work toward creative solutions to meet the complexity of challenges since the world is characterized by diversity and pluralism. In a broader perspective, education enables a society to be globally competitive. Thus, sufficient resources must be focused toward improved educational quality. It would be dangerous for students to exit the system without any learning gains.

Consequently, the Kenya government ensures that citizens access education by making it affordable even to the very poor through loans, bursaries, grants and direct funding as is the case in primary and secondary schools. Individuals have the responsibility to support the education of their children. Indeed, education is a human right for every child of school-going age and violation is chargeable in the court of law. 
Observably, the nature of education today appears to be enmeshed with the consumerist culture. Commercialization of culture and society and the impact of mass media drive people to become consumers. Activities are largely designed to celebrate consumption and elaborate its significance. In fact, commodities of consumption are not only the objects to meet the needs, but they are symbols of social identity and personality. In the interest of this paper, it is argued that education has become a commodity of heightened consumption value with emphasis on certification rather than knowledge and skills. This poses crucial questions of funding and quality that call for thoughtful discourse.

\section{LITERATURE REVIEW}

This section examines the concept of consumerism, the relationship between consumerism and education, and how this relationship has affected the funding and quality of education.

\section{The concept of Consumerism}

This is basically the aspect of consuming. It is the belief that it is good for people to spend a lot of money on goods and services. This is hinged on the assumption that increasing consumption is economically desirable, and that a progressively greater level of consumption is beneficial to the consumers. The concept of consumerism got its spur in the Industrial Revolution when scarcity of resources was overcome and a huge variety of goods in unlimited amounts became available to a wide range of people (Palahniuk, 2010). The unlimited access to products at low cost birthed the era of mass consumption. In the new type of economy that was created-capitalism, money became the mediator between desire and satisfaction, and the middle class suddenly had lots of it to buy commodities in excess of their needs.

Palahniuk (2010) further observes that at the outset of capitalism, production governed consumer behavior and people purchased based on need. With time however, consumption begun to drive the market as people consumed based on affordability. 'Why have the old model when the latest was more efficient?'But before long, people transitioned to buying new models based on appearance rather than functions. It was a full blown consumer(ist) culture. Understandably therefore, this is a culture which spends enormous amounts of resources on advertisement with the explicit goal of making people to want more. Thus, while the purpose of the economic system is to make people more satisfied, advertising makes them less satisfied. Also, the consumerist culture emphasizes planned obsolescence and disposability such that products are designed in a way to lose value soon after purchase, and consumers will want to throw them away for perceived better ones. In fact, advertising focuses on our insecurities so we feel the need to obtain the product, service or image to confirm our self-worth. The whole concept is psychological in nature, as it appeals to our emotions rather than reason. And because this is a culture, it permeates all aspects of life including education.

\section{Consumerism and Education}

In the consumerist culture, commodities of consumption are not only the objects to meet needs, but they are also symbols of social identity and personality (Jean, 2001). In essence, consuming desires and tastes define the consumer's social rank and personal qualities. Life is valued on the basis of consuming lifestyles. It therefore appears that education helps to shape the image of consumers.

School is perceived as a market where education (knowledge) is commercialized. It produces commodities which students are expected to consume. Consequently, the curriculum is designed to meet the consumption trends of the social market if not for today, then for the future. Students are therefore allured in definite ways with the promise to cater for their tastes 
and offer them satisfaction. With the understanding that production is alienating, we all seek fulfillment through consumerism. Since education is known to be the bridge to better social status, an equalizing agent of sorts, its consumption at all levels has gone a notch higher. A lot of people now seek an education to 'fit in', rather than for what the knowledge can enable them to do. It is just satisfying to get that sort or level of education even though it may not really be needed. Acquisition of competencies and mastery of skills do not rank top. This is so true among the Kenyan political class who can only be allowed to contest for certain positions based on some specified level of education and certification.

The whole arrangement goes against the noble course propagated by the World Bank, UNESCO, and other funding agencies which focus on growth, development and poverty reduction as contingent upon the skills that people acquire. Even at the individual level, while a diploma may open doors to employment, it is the worker's skills that determine his or her productivity and ability to adapt to new technologies and opportunities (World Bank, 2011). The rise of consumerism seems to progressively obscure this goal. It is at this point that the question of funding and quality arises. Is the heavy investment in education necessary if the learners' focus is consumerist rather than instrumental? And with this focus, does the quality matter?

\section{Consumerism and Education funding}

Studies have established that spending on education is an investment with a return (Hewlette n.d). Millions of poor families have sacrificed scarce resources to put their children through school with the hope that education will draw them out of poverty. Unfortunately however, the increasing number of the educated unemployed has shattered this notion bringing education funding into jeopardy. With many other consumables on which resources can be spent, funding of education faces stiff competition.

Since the late 1980s, there has been a significant shift in the Kenya government expenditure priorities from social programmes to the economic sector. This was necessitated by economic stagnation and the World Bank-driven structural reform which emphasized less investment in education, health and other social services (Kamotho, 2014). The policy has mostly affected funding of education at the tertiary level. Diminished government funding for students who qualify to join university (through restrictive subject clustering) has necessitated the expansion of private universities from 2 in 1980 to the current 27, with 14 of them fully accredited through issuance of charters. The private universities enroll about 50,000 students (30\%) of all students attending university. The World Bank encourages private universities as the more costeffective way of easing pressure on the public higher education system since they do not add significantly to government costs. It is however not lost to all, that private universities are expensive. This expansion is therefore not bereft of consumerist overtures.

\section{Consumerism and Education Quality}

Education is not only a means to an end, but also an end in itself. Simply put, it is both a process and a product (Digolo, 2006). As a process, it denotes continued acquisition of knowledge, skills, values and ideals required to play significant roles in society. It involves developing potential in an individual and molding him to achieve some desirable goal for his own good and for the good of society. As a product, it is the aggregate of what has been learnt and expressed in terms of abilities, attitudes, and other socially acceptable behavior. Both these perspectives are taken into account as success is determined by the quality of education received against the backdrop of a consumerist culture. 
In line with consumerism, learning opportunities have been expanded. The result has been increased enrolment at all levels of learning. In primary school, the gross enrolment rose from about 9,757,000 in 2012 to 10,280,000 in 2016 (Republic of Kenya, 2016). The increase in secondary school within the same period was from about $1,914,000$ to $2,723,000$. In the university (public and private together), the total enrolment more than doubled between 2012 and 2016 to 539,749 (Mukhwana et al., 2016). Such numbers speak well of a nation whose goal at independence over 50 years ago, was to eradicate illiteracy. But how about the ensuing quality of the education, given that resources (physical and human) have not expanded at equal speed?

There has been debate that many children are not learning the basics of literacy, numeracy and critical thinking during their foundational years. A survey by Uwezo Kenya in 2013 revealed a grim picture of primary school education in public schools (Opiyo, 2013). The report gave several findings: that some pupils $(11 \%)$ in Standard Eight could not solve Class Two level mathematical division questions; more than half (70\%) of Kenyan pupils in Class Three could not read Class Two work; more than 50\% of children in Class Four and Five and $21 \%$ of their counterparts in Class Six to Eight could not comprehend a Class Two level story even when they read it; and $20 \%$ of learners in Class Six to Eight could not tell the meaning of the colours of the Kenyan flag. This kind of situation may be a result of a combination of factors such as high teacher-student ratio, insufficient learning resources, teacher incompetence and the like. It is evidence of low quality education and if not addressed, will result in a serious crisis in the future.

Standards at universities have also been affected due to increased demand for higher education and the concomitant numbers. Being well aware of this, the Education Cabinet Secretary has called on the Commission for University Education to ensure quality by emphasizing on lecturers with $\mathrm{PhDs}$ and undertaking regular inspection. It can be argued that consumerism may have some degree of influence in the tumbling standards. At higher levels, students think that since they are paying a given amount of cash they deserve a passing grade without putting much effort into their studies. Such students with consumerist attitude have unrealistic expectations, mostly created by advertisement, and think that knowledge is consumed. However, this is not so. It must be regenerated, reinterpreted, and co-constructed with the help of the instructor. This calls for critical thinking. But through media effect, certain brands (courses) are made popular and hence attract even the under-qualified as long as they can pay. Such students driven by consumerism find it difficult to learn the principles they need to understand before truly gaining knowledge to be successful in their chosen careers. Under examination situations, they are likely to cheat just so they can get the certificate.

Thus, consumerism has become a huge demand making it easier for people to attend school and continue their education. Underneath is the desire to improve the purchasing power, not necessarily to offer better service. As a result, people are putting in their resources to obtain an education even in their wee years of service. Those who can afford can have it. Parents too have changed by not being involved with their children's education even though studies have shown that parental involvement is paramount for learning (Garcia \& Thornton, 2014; Goforth et al., 2014; Hornby \& Lafaele, 2011; Sapungan \& Sapungan, 2014; Thill, (2017). They believe that since they are paying for their children to attend school, school should offer the grade. Consequently, schools are being transformed, as earlier noted, into commercial rather than public spheres as students become subject to the whims and practices of marketers. Thus, with the entry of profit motive into the education arena, school reform has little more than a business agenda. 
Alignment of education with market trends appears to be rated over and above acquisition of the requisite knowledge for better performance. Thus, in cases where the consumerist culture is driving the practice, there appears to be an intertwined relationship between funding and quality, whichever way one looks at it. My submission is that it could mean pay more, obtain better; or, and most likely, pay and have it your way since the customer is always right. When students are treated like customers, they behave likewise. The likely scenario is that before long, the customer will control the entire show of this important social process hence ramifications for quality.

\section{METHODOLOGY}

Driven by the specific objective to determine the state of Kenyan education in the wake of consumerism, the mode of data collection was basically content analysis. Information on enrolment and funding was obtained from Ministry of Education booklets for basic and university education. Literature on consumer habits and market trends was also used. Interaction between education and consumerism was the conclusion of the author.

\section{FINDINGS AND DISCUSSION}

The consumerist culture is evident in education in Kenya. It thrives on intellectual inactivity where other people think and create whatever we need and the rest pay for access. Today, many parents and students interact with school with a consumerist mind. That money can buy any kind of education. Securing the best school where grades are assured is the common practice. More often, these are popular private institutions which turn out to be quite expensive. However, the products of these institutions do not always fare better than those from public ones in view of performance in the market. The underlying impetus is affordability and assurance of a high passing grade, not necessarily more knowledge and skills. This itself is a departure from global recommendations for education.

According to UNESCO, education should be a means to empower children and adults alike to become active participants in the transformation of their societies. Learning should also focus on the values, attitudes and behaviours which enable individuals to live together in a world characterized by diversity and pluralism. Consumerism on the other hand seems to do the direct opposite. People are tempted to concern themselves about their own consuming desires and selfish short-term ego gratification (Jean, 2001). This means that calculating, competing and owning become the target of individuals without caring about the common well-being.

Consumerism therefore shapes and refashions the self-identities and self-expectations of people and provides them with a new lens through which to evaluate life-amount of consumables they own. As a result of the consumerist culture, education abandons its intrinsic values in the cultivation of all-round persons, both morally and intellectually. What is happening is clearly captured by Henry (2000). He opines that schools are being transformed into commercial rather than public spheres as students become subject to the whims and practices of marketers whose agenda has nothing to do with critical learning and a great deal to do with restructuring civic life in the image of market culture. Education is therefore to meet a new socially constructed goal of status rather than service. This may explain the problem of the educated under-performing which various institutions grapple with today.

An expose by Kairu (2014) on the English language communication deficiency at the workplace illustrates this well. Scholars related this to the poor instruction at the primary school level where teachers themselves had failed the subject, but also to the secondary treatment (in favour of technical skills) that the subject received at tertiary level. With this kind of scenario, 
education both as a process and a product fails the quality test. Whether the 'consumer' on the other end gets satisfied is a question that begs an answer. But as earlier noted, to satisfy the consumer is not the ultimate goal of consumerism. One should only be satisfied for a short while, and want a better version again. The cycle should be continued. This should alarm educationists and make them rise to defense. How about an educational revolution?

\section{Which Way for the Education Sector?}

According to the World Bank Group Education strategy 2020, education is fundamental to development and growth. Besides, access to education which is a basic human right enshrined in the Universal Declaration of Human Rights and the United Nations Convention on the Rights of the Child, is also a strategic development investment. This therefore means that although funding may have shrunk especially in Kenya, it continues to hold an important position in the broader development agenda. In fact, the World Bank's financial support for education has risen over the decade since the MDGs were established, surging to more than $\$ 5$ billion in 2010 (World Bank, 2011).

The post-2015 education agenda is in the pipeline and the UNESCO Institute for Statistics is coordinating a technical advisory group that includes experts from UNICEF, the World Bank, the OECD, the EFA Global Monitoring Report and UNESCO. Its task is to identify and review existing indicators that could help to develop new measures to monitor global education progress. This will be done while at the same time offering flexibility to respond to countries aspirations (UNESCO, 2013). It is hoped that in time, education should be a stand-alone goal and yet be integrated into other development goals. This highlights the significance of education and gives reason to work towards directing it to its transformative and holistic role in society. While consumerism propagates inequality and exclusion, education should reflect equity and inclusiveness. Education must therefore not be viewed from a consumerist perspective. Learning for all means ensuring that all students, not just the privileged, acquire the knowledge and skills they need to live happy productive lives. This means a new education funding strategy and emphasis on quality.

\section{References}

Agarwal, A (n.d). Essay on the role of education in society. Retrieved www.preservarticles.com/201107048804/essay-on-the-role-of-education-in-society.html Digolo, O.O (2006). The challenges of education in Kenya in the $21^{\text {st }}$ century. The Educator, 1(1),xv-xxviii.

Garcia, L. E \& Thornton, O. (2014). The enduring importance of parental involvement. Retrieved http://Neatoday.org/2014/11/18the-enduring-importance-of-parentalinvolvement-2/

Goforth, K.; Noltemeyer, A, Patton, J. Bush, K. \& Bergen, D. (2014). Understanding mathematics achievement: An analysis of the effects of student and family factors. Educational Studies,40(2), pp196-214.

Hewlett (n.d). Quality education in developing countries. Retrieved www.hewlett.org/programs/global-devt.../quality-education

Henry, G. (2000). Stealing innocence: Youth, corporate power and the politics of culture. New York: Palgrave.

Hornby, G \& Lafaele, R. (2011). Barriers to parental involvement in education: An explanatory model. Educational Review, 63(1) 37-52.

Jean, B. (2001). The systems of objects. In Poster, M (Ed.). Selected writings. Stanford: Stanford university press. 
Kairu, P (2014, April 21). Why experts are in a panic over English. Daily Nation (The Springboard), p.1.

Kamotho, K. (2014, March 14). How Kenya became a hub of private universities. Daily Nation (After KCSE), p.5.

Mukhwana, E., Oure, S., Kiptoo, S., Kande, A., Njue, R., Too, J.,\& Some, D. K (2016). State of University Education in Kenya. Discussion paper 04. Nairobi, Kenya.

Opiyo, D. (2013, July 23). Pupils can't read or write: Survey. Daily Nation, p.60.

Palahniuk, C. (2010). Things you own end up owning you. Persuasive essay on consumerism. Retrieved http://www.tailoredessays.com/samples/essay-on-consumerism.htm

Republic of Kenya (2007). Ministry of Education Statistical Booklet2003-2007. Nairobi: Government printers.

Republic of Kenya (2016). Ministry of Education. Basic Education Statistical Booklet.

Sapungan, G. M \& Sapungan, R. M (2014). Parental involvement in child's education: Importance, barriers and benefits. Asian Journal Management Sciences and Education, 3(2): 42-48.

Simiyu, C.K. (2012, March). Mass market education in Kenya: An evaluation of teacher preparedness. A paper presented at the National Conference of Education in Tanzania $\left(28^{\text {th }}-30^{\text {th }}\right.$ March).

Thill, R. F. (2017). How parental involvement benefits kids. Retrieved https://www.verywellfamily.com/how-parent-involvement-benefits-kids-3288064

UNESCO (2013). Beyond 2015: The education we want. Retrieved www.unesco.org

World Bank Group Education Strategy, (2011). Retrieved www.worldbank.org 